\title{
The Effect of Salesforces Satisfaction on the Mainstay Farmer Partner Performance in East Java
}

\author{
Herry Kristanto \\ \{herry.kristanto2@gmail.com ${ }^{1}$ \} \\ Doctorate Program of Management Science, Brawijaya University, 65145, Indonesia ${ }^{1}$
}

\begin{abstract}
The performance of the salesforces of the mainstay farmer partners is not yet high. The level of technology adoption has not been maximal. Productivity is still low. Sales growth and profitability have not been significant in the last five years. This is thought to be related to salesforces satisfaction. The purpose of this study is to determine the effect of salesforces satisfaction on the performance of mainstay farmer partners in East Java. The study is conducted using quantitative methods. The analysis unit is the mainstay farmer partner in East Java. Data is collected in 2020. PLS is used to test the hypothesis. The result showed that salesforces satisfaction has an effect on the performance of the mainstay farmer partners. The job description is an aspect that has a more dominant influence than remuneration and career in improving the performance of mainstay farmer partners in East Java. The results of this study have implications for companies associated with mainstay farmer partners that to improve the performance of mainstay farmer partners, it is necessary to establish salesforces fulfillment, especially in terms of the job description.
\end{abstract}

Keywords: Salesforces satisfaction, performance, mainstay farmer partner

\section{Introduction}

Agricultural companies which are mostly dominated by Multi-National Companies originating from the United States or Europe such as Corteva, Syngenta, Bayer, FMC, UPL, Advanta are usually dealing with a small number of farmers with large land ownership so that in their home country they only need a little field workers/agronomist. The limited number of field workers was circumvented by the formation or selection of Farmer Partners by several companies engaged in agriculture to be able to assist their organic or agronomist extension workers in carrying out several field activities to convince and influence farmers in choosing the best production facilities such as seeds, fertilizers, pesticides and also market access.

These partners are chosen by each company with various criteria such as having a kiosk/farmer's shop that is strategically located, having field workers to help market agricultural production facilities, creating demand, having sufficient capital and usually being a community leader, and local people who are respected by the surrounding community/society.

Until now, their existence, success in influencing farmers to use agricultural means products and modern agricultural technology that support the creation of food security varies from region to region because there is no standard for companies engaged in agriculture either MultiNational Companies (MNC), State Owned Enterprises, or National Companies, both in terms 
of criteria for selecting Farmer Partners, training that must be provided, as well as the number of incentives that must be provided and also helping to gain access to capital to support their business growth.

The phenomenon shows that the performance of the salesforces of the mainstay farmer partners is not yet high in terms of the level of adoption of modern agricultural technology. The average agricultural productivity is still low. In addition, sales growth and profitability have not been significant in the last five years. The term "employee performance" means personal work performance after exerting the necessary effort in the job associated with getting a meaningful job, the profile involved, and loving co-workers/employers [8]. While related to marketers, Baldauf et al. [2], defines the performance of salesforces as an evaluation of the person's contribution to achieving stated organizational goals.

This condition is alleged to be related to the lack of satisfaction of salesforces. The phenomenon shows that salesforces often easily move from one agricultural company to another because they are tempted by offers made by competing companies. This indicates there was dissatisfaction in the previous workplace. Based on description above this study purpose to determine the effect of salesforces satisfaction on salesforces performance.

\section{Literature Review}

Strenitzerová and Achimsk [11] argue that satisfying employee requirements and providing excellent working circumstances is the best way to achieve success, sustainability, competitiveness, and increased company efficiency. In addition, the quality of work-life has a positive and significant effect on employee job satisfaction and employee loyalty.

The majority of definitions imply that job satisfaction is a suitable irrational response to employment [9]. Job satisfaction refers to an individual's emotional reaction to many aspects of work [5].

Sila and Sirok argued that [10] the relevant definition of job satisfaction according to Spector, namely how individuals feel about their jobs and various facets of their jobs., Spector emphasizes connection between negative and positive emotions as the impact on employee behavior and performance, which influences organizational outcomes. Therefore, Sila and Sirok [10] refer to Spector's job satisfaction survey in measuring job satisfaction in their study which includes the following aspects: Payment; Supervision; Fringe benefits; Promotion; Contingent rewards; Rules; instructions; Communication; Co-workers; Nature of work; and working conditions.

Furthermore, based on a review of various literature, Strenitzerová and Achimský [11] measure employee job satisfaction using three dimensions, namely: a. Satisfaction with the job description; specifically, the degree to which an employee is satisfied with the job's substance; b. Satisfaction with employee remuneration; which includes satisfaction with wages and financial value; and c. Workers are satisfied with their professional and career development; employees are satisfied with their professional and career development. The dimensions from Strenitzerová and Achimský [11] are used to test the satisfaction variables of salesforces in this study.

Employee performance is a source of strategic excellence for the company [13]. Diamantidis and Chatzoglou [4] Employee performance is defined as the degree to which an employee's productivity satisfies the company's performance criteria. They studied three variables affecting employee performance: 
a. Factors affecting the firm/environment, such as managerial support, training culture, organizational culture, and environmental dynamic (perceived instability).

b. Factors relating to the jobs, such as the work atmosphere, communication with coworkers, and job autonomy.

c. Factors affecting employees: proactiveness, adaptability, intrinsic motivation, skill flexibility, commitment, and skill level.

According to Pradhan and Jena [8], Three factors define employee performance: task performance, adaptable performance, and contextual performance. Meanwhile, for employees as marketing personnel, Baldauf et al. [2], marketers' performance is an evaluation of the person's contribution to achieving stated organizational goals. To evaluate the performance of marketers, according to Barker in Aqmala and Ardyan [1], a salesperson's performance can be evaluated using factors that can be controlled by the salesperson itself and can be measured through the total volume of sales and achievement of sales targets.

According to this concept, the dimensions used to evaluate salesforce performance in this study refer to Diamantidis and Chatzoglou [4] and Barker in Aqmala and Ardyan [1], and include the following dimensions: firm/environment-related factors, job-related factors, and employee-related factors, and achievement of sales targets.

Money and Graham [6] established a relationship between salesperson satisfaction and performance by testing a causal model of salesperson performance and satisfaction using data gathered in Japan and the United States. Their findings show that satisfaction and sales force performance are causally related. A hypothesis about sales objectives is formed based on the information above:

H: Marketers' satisfaction affects the performance of marketers

\section{Method}

This study used a quantitative method with a cross-sectional survey design. A crosssectional design survey is a survey where the research sample is taken at one time (not continuous). By using reliable farmer partners as the unit of analysis, the population of this study is the mainstay farmer partners in East Java, so that the unit of observation is the management. Samples were taken from as many as 50 marketers in East Java. The data was processed using Partial Least Square (PLS).

\section{Results and Discussion}

\subsection{Analysis of structural model (inner model)}

Table 1. Test of outer and inner model

\begin{tabular}{llllc}
\hline Variable & R Square & $\begin{array}{l}\text { Cronbachs } \\
\text { Alpha }\end{array}$ & $\begin{array}{l}\text { Composite } \\
\text { Reliability }\end{array}$ & Q square \\
\hline Salesforces Satisfaction & - & 0.959 & 0.966 & 0.798 \\
Salesforces Performance & 0.461 & 0.979 & 0.982 & 0.797 \\
\hline
\end{tabular}

Source: SmartPLS 2.0 
The study of structural models (inner models) elucidates the relationships between latent variables. The inner model was assessed using the Goodness of Fit (GoF) method, which quantifies the difference between observed and predicted values. This is demonstrated by the $\mathrm{R}$ square on endogenous structures and the $\mathrm{Q}$ square (prediction relevance), also known as StoneGeisser's. Q square values of 0.02 (minor), 0.15 (medium), and 0.35 (large) were obtained for the endogenous construct using a reflecting indicator. According to Chin [2, R square values of 0.67 (strong), 0.33 (medium), and 0.19 (weak) were used (weak). As the independent variables in Table 1 satisfy the strong criterion $(>0.67=$ strong), and the Q square values satisfy the high criteria, it may be concluded that the research model is supported by empirical data or that the model is fit.

\subsection{Analysis of measurement model (outer model)}

The analysis of the measurement model (outer model) reveals the connections between the latent variables (indicators) and each latent variable. A validity and reliability analysis is conducted to ascertain the latent variables and indicators that were used to construct the dimension. Cronbach's Alpha is used to assess the reliability of a dimension when it comes to measuring variables. When Cronbach's Alpha is better than 0.70 (Nunnaly, 1994), the dimensions and indicators are considered reliable when used to measure variables. Composite reliability and Cronbach's Alpha values more than 0.70 suggest that all variables in the model should fulfill the criterion for discriminant validity. Then, one may deduce that all of the variables are extremely trustworthy. Cronbach's Alpha is greater than 0.7 and Composite Reliability is greater than 0.7 , suggesting that all variables have reliable dimensions and indicators.

The outer model's output is shown in Table 2 for each indicator dimension. With regard to the second order, This research model explains the link between dimensions of latent variables and indicators through the use of the derived loading factor.

Table 2. Loading factor of latent variable-dimension-indicator

\begin{tabular}{llccl}
\hline $\begin{array}{c}\text { Variable- } \\
\text { Dimension }\end{array}$ & \multicolumn{1}{c}{ Indicator-Dimension } & $\lambda$ & SE $(\boldsymbol{\lambda})$ & t-value \\
\hline Salesforces & Salesforces Satisfaction -> job description & 0.989 & 0.002 & 488.372 \\
Satisfaction - & SATIS1 <- job description & 0.863 & 0.038 & 22.948 \\
& SATIS2 <- job description & 0.883 & 0.016 & 53.834 \\
& SATIS3 <- job description & 0.941 & 0.011 & 82.610 \\
& Salesforces Satisfaction -> remuneration & 0.979 & 0.005 & 199.854 \\
& SATIS4 <- remuneration & 0.940 & 0.009 & 98.987 \\
& SATIS5 <- remuneration & 0.937 & 0.010 & 90.282 \\
& Salesforces Satisfaction -> career growth & 0.982 & 0.004 & 272.632 \\
& SATIS6 <- career growth & 0.914 & 0.016 & 57.611 \\
& SATIS7 <- career growth & 0.901 & 0.022 & 40.483 \\
\hline Salesforces & Salesforces Performance -> Firm/environment- & 0.991 & 0.002 & 461.425 \\
Performance & related factors & & & \\
& PERF1 <- Firm/environment-related factors & 0.913 & 0.023 & 39.475 \\
& PERF2 <- Firm/environment-related factors & 0.952 & 0.012 & 81.178 \\
& PERF3 <- Firm/environment-related factors & 0.937 & 0.013 & 73.896 \\
& PERF4 <- Firm/environment-related factors & 0.930 & 0.018 & 51.430 \\
& Salesforces Performance -> Job-related factors & 0.981 & 0.004 & 233.329 \\
& PERF5 <- Job-related factors & 0.968 & 0.010 & 100.561
\end{tabular}




\begin{tabular}{clccc}
\hline $\begin{array}{c}\text { Variable- } \\
\text { Dimension }\end{array}$ & \multicolumn{1}{c}{ Indicator-Dimension } & $\boldsymbol{\lambda}$ & $\mathbf{S E}(\boldsymbol{\lambda})$ & t-value \\
\hline & PERF6 <- Job-related factors & 0.946 & 0.012 & 77.195 \\
& PERF7 <- Job-related factors & 0.965 & 0.009 & 113.305 \\
& Salesforces Performance -> Employee-related & 0.956 & 0.009 & 109.322 \\
& factors & & & \\
& PERF8 <- Employee-related factors & 0.923 & 0.017 & 54.970 \\
& PERF9 <- Employee-related factors & 0.945 & 0.016 & 60.126 \\
PERF10 <- Employee-related factors & 0.804 & 0.044 & 18.341 \\
PERF11 <- Employee-related factors & 0.838 & 0.081 & 10.332 \\
Salesforces Performance -> Target & 0.917 & 0.015 & 63.103 \\
PERF12 <- Target & 0.989 & 0.003 & 339.258 \\
PERF13 <- Target & 0.989 & 0.003 & 392.879 \\
\hline
\end{tabular}

The outer model of dimensions expressed in terms of their indicators reveals that the indicators are valid at $\mathrm{t}=2.01(\mathrm{t}$ table at $=0.05)$. The result of the latent variable measurement model on their dimensions indicates the validity of dimensions in measuring latent variables (Figure 1).

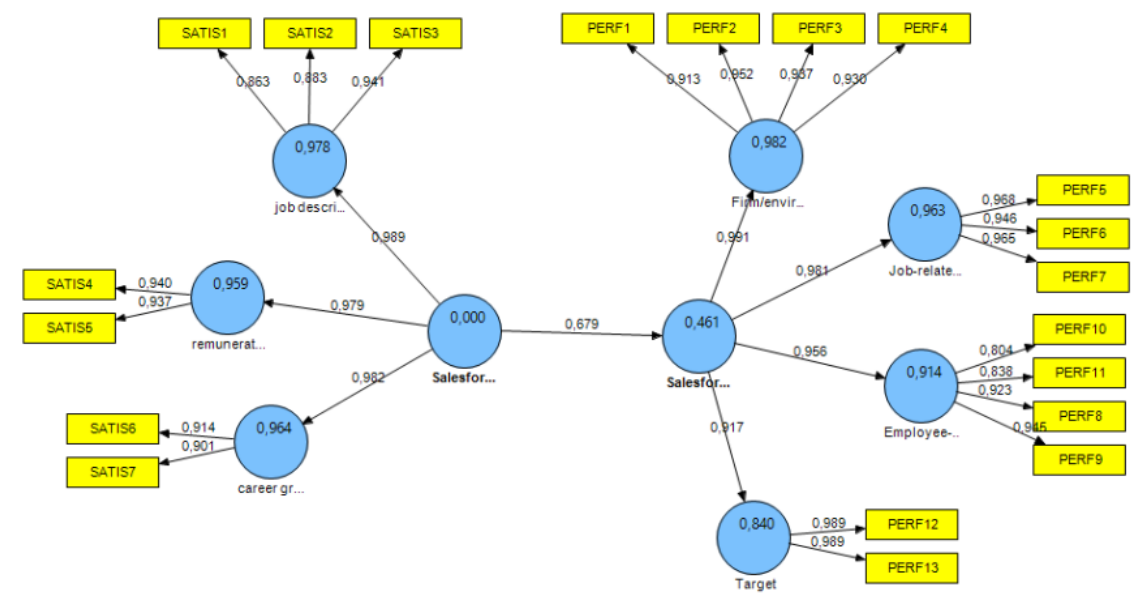

Fig. 1. Path diagram of research model

Then, based on the research framework, a structural model was developed:

$\mathbf{Y}=\mathbf{0 . 6 7 9 X 1}+\zeta_{1}$

$\mathrm{X} 1=$ SalesForces Satisfaction

$\mathrm{Y}=$ SalesForces Performance

$\zeta 1=$ Residual

Below is the result of hypothesis testing both simultaneous and partially.

Table 3. Hypothesis testing

\begin{tabular}{llllll}
\hline Hypothesis & $\gamma$ & SE $(\gamma)$ & t-value & $\mathbf{R}^{2}$ & Conclusion \\
\hline $\begin{array}{l}\text { Salesforces Satisfaction } \\
\text { Salesforces Performance }\end{array}$ & 0.679 & 0.097 & 7.012 & 0.461 & $\begin{array}{l}\text { Hipotesis } \\
\text { accepted }\end{array}$ \\
\hline
\end{tabular}

*Significant at $\alpha=0.05(\mathrm{t}$ table $=2.01)$ 
Table 3 demonstrates that salesforce satisfaction has a substantial impact on salesforce performance, with an R2 of 46.1 percent. According to the findings of hypothesis testing, the following can be regarded as a research finding in (Figure 2).

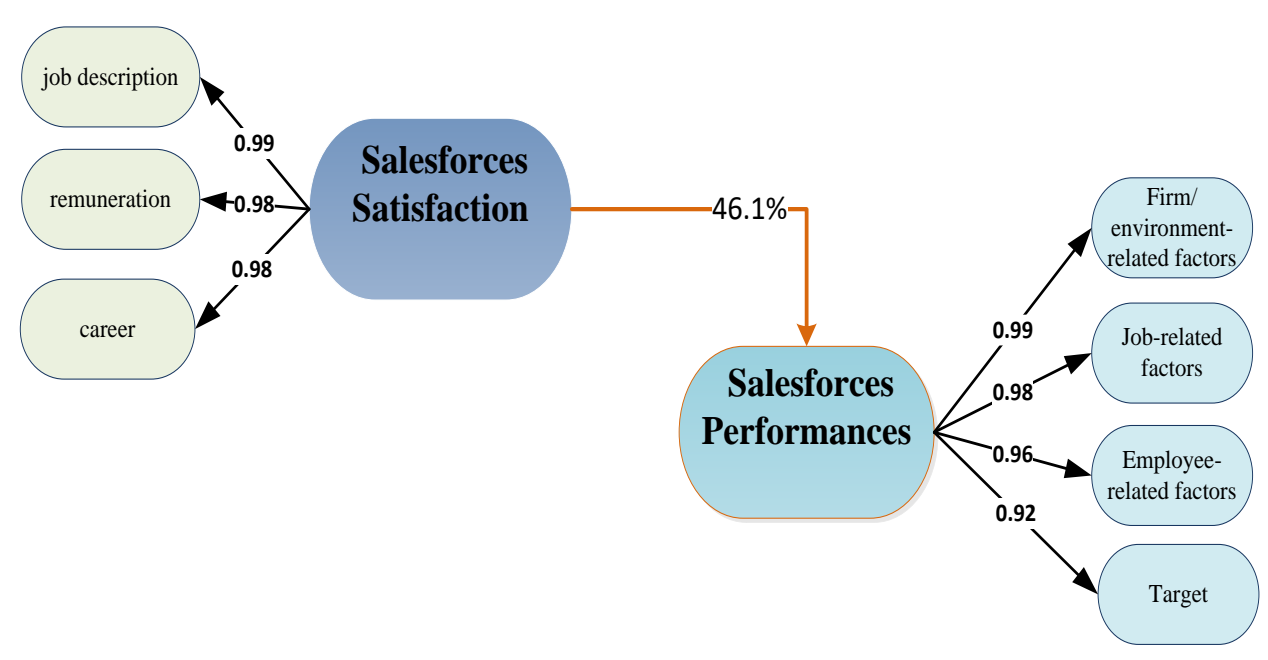

Fig. 2. Research finding

According to the findings of this study, salesforce satisfaction has an effect on salesforce performance. Three dimensions contribute to Salesforce's happiness. The test findings indicate that contentment with the job description is the primary factor that contributes to salesforce satisfaction, which has an effect on salesforce performance. Satisfaction with the job description include individual job descriptions, teamwork descriptions, and the job assessment system. Satisfaction with pay include salary as well as bonuses/fees. Employee happiness with professional and career development represents employee satisfaction with professional and career development.

Satisfaction with these three aspects is proven to be able to increase salesforces performance. This is consistent with the results of research by Money and Graham [6] which show a causal relationship between satisfaction and the performance of marketers. This is also consistent with Spector in Sila and Sirok [10] Several believe that job satisfaction refers to how individuals feel about their jobs and various elements of their jobs. Spector focuses in particular on the link between negative and positive emotions and their impact on employee behavior and performance, which in turn has an effect on organizational results.

The result of this study has practical implications for the management of agricultural companies in their efforts to improve the performance of salesforces. Where this can be done by increasing the satisfaction of salesforces in terms of job descriptions, remuneration, and career growth and professionalism. 


\section{Conclusion}

This study aims to determine the effect of salesforces satisfaction on salesforces performance. The result of this study indicates that salesforces satisfaction is proven to effects salesforces performance. Satisfaction with the job description is the main aspect that results in satisfaction for salesforces which has an impact on salesforces performance. The results show that provide practical implications for the management of agricultural companies that efforts to improve the performance of salesforces of mainstay farmer partners can be done by increasing their satisfaction in terms of job descriptions, remuneration, and career growth and professionalism.

\section{References}

[1] Aqmala, D \& Ardyan, E. (2019). How Does a Salesperson Improve Their Performance? The Important Role of Their Customer Smart Response Capability. Gadjah Mada International Journal of Business, 21(2): 223-241.

[2] Baldauf, A., and Cravens, D. W. (2002). The effect of moderators on the salesperson's behavior performance and salesperson's outcome performance and sales organization's effectiveness relationships. European Journal of Marketing, 36 (11/12): 1367-1388.

[3] Chin, W. W. (1998). The Partial Least Squares Approach to Structural Equation Modeling. Modern Methods for Business Research, 295, 336.

[4] Diamantidis, A. D. \& Chatzoglou, P. (2019). Factors affecting employee performance: an empirical approach. International Journal of Productivity and Performance Management, 68(1), pp.171-193, https://doi.org/10.1108/IJPPM-01-2018-0012.

[5] Kreitner, R. \& Kinicki, A. (2001). Organizational Behavior. Fifth Edition. Irwin McGraw-Hill.

[6] Money, R. B. \& Graham, J.L. (2010). Salesperson Performance, Pay, and Job Satisfaction: Tests of a Model Using Data Collected in the United States and Japan. Source: Journal of International Business Studies, 30 (1), 149-172 Published by: Palgrave Macmillan Journals Stable URL: http://www.jstor.org/stable/155273.

[7] Nunnally, B. I.H. (1994). Psychometric Theory. New York: McGraw Hill.

[8] Pradhan, RK \& Jena, LK. (2017). Employee Performance at Workplace: Conceptual Model and Empirical Validation. Business Perspectives and Research 5(1) 1-17 K.J. Somaiya Institute of Management Studies and Research SAGE Publications sagepub.in/home.nav DOI: $10.1177 / 2278533716671630$

[9] Rast, S. \& Tourani, A. (2012). Evaluation of Employees' Job Satisfaction and Role of Gender Difference: An Empirical Study at Airline Industry in Iran. International Journal of Business and Social Science, 3(7).

[10] Sila, E \& Sirok, K. (2018). The Importance of Employee Satisfaction: A Case Study of a Transportation and Logistics Service Company. DOI: 10.26493/1854-4231.13.111-136.

[11] Strenitzerová, M. \& Achimský, K. 2019. Employee Satisfaction and Loyalty as a Part of Sustainable Human Resource Management in Postal Sector. Sustainability, 11, 4591; doi: 10.3390/su11174591

[12] Evanschitzky, H., Ramaseshan, B., Woisetschläger, D.M., Richelsen, V., Blut, M. \& Backhaus, C. (2011). Consequences of customer loyalty to the loyalty program and to the company. Journal of the Academic Marketing Science.

[13] Wright, P.M. and Snell, S.A. (2009). Human resources, organizational resources, and capabilities. In Storey, J., Wright, P. and Ulrich, D. (Eds), The Routledge Companion to Strategic Human Resource Management, Routledge, London, pp. 345-356. 